\title{
DYNAMICS OF CRYSTAL LATTICE WITH NON-TETRAEDRICAL SITE IN KEATING MODEL
}

\author{
Aleksey B. Gordienko*, Kirill A. Gordienko, Anatoliy V. Kopytov
}

Kemerovo State University, Krasnaya Str. 6, Kemerovo, 650043 Russian Federation

Received September 30, 2016;

* e-mail: gordi@kemsu.ru

Accepted in revised form October 25, 2016;

Published December 30, 2016

\begin{abstract}
Keating Model to estimation of the crystal lattice dynamics with the atomic coordination different from that of tetrahedral. The general model statement is considered in view of the long-range pattern of Coulomb interaction, software support of estimations with total consistency and accuracy assessment in terms of test systems to be standard for the Keating Model, and calculation results are given with the analysis of the crystal phonon spectrum structured like the mineral salt and fluorite. It is shown that the best choice of the model parameters will result in values for compounds of the structure above that are well consistent with experimental data, including acoustic vibration frequency range, where the Keating Model normally results in the increased values thereof.
\end{abstract}

Key words: lattice dynamics, Keating Model, force coefficient, phonon spectrum, atomic site

DOI: $10.21603 / 2500-1418-2016-1-2-108-113$.

\section{INTRODUCTION}

The Keating Model [1] is one of the most popular and widely used approaches to describe the short-range interaction between atoms and crystalls. Along with the expansion [2] that accounts for the long-range pattern of the Coulomb interaction in compounds having ionic constituent of the chemical bond, the method [1] today is successfully used to calculate elastic constants, phonon spectrum and concurrent features of quite the wide range of the system (perfect and imperfect crystals, heterostructures, alloys), and it is also the theoretic base for a range of more common methods to consider, in particular, combined interactions or anharmonicity effects. The Keating Model is one of alternatives of valence force field methods (VFF), though it's wording is primarily based on the demand of invariance of the stress-free crystal potential energy towards rotations. This suggests exclusion of discordance possibility of the VFF method when it is used for periodic system and, at the same time, retention of the physical transparency when describing interactions and simplicity of calculations. Starting from the initial work [1], the model is applied to compounds with tetrahedral site, such as diamond, sphalerite and of this kind where each atom has 4 bonds with the nearest neighbors. It should be noted that initially, even for such crystals, the Keating model was used to calculate elastic constants, and one of first works where vibrational spectrum was estimated on the same basis is [3], where analytic expressions of the dynamic matrix have been obtained for the diamond followed by frequency ranges for the three points of the Brillouin zone. Also, the latticed dynamics was also evaluated within the Keating Model of more complicated structural types of compounds, like in [4-8] for crystals with the structure of copper pyrites, [9] for the mono-layer superlattice (GaAs)1 (AlAs)1. At once, works are hardly reported where the Keating Model is used in its authentic statement to calculate the vibrational spectrum of crystals of the structure different from that of diamond-like. This is with the exception of the work [10] that shows results for the zirconium carbide $(\mathrm{ZrC})$ with the rock salt structure, and [11-15] though the VFF method for such crystals is quite successfully applied, for example, [16-20], where the 7-parameter bond-bending force model, BBFM, is considered. Thus, the study of the Keating model applicability to compounds with atoms of the site other than tetrahedral, is quite relevant and interesting challenge that sets main objective of this work. Below, the following will be described: a general description of the Keating Model, features of the software support and calculation results of the phonon spectra for test systems, having the diamond-like structure, as well as the parameters, calculations and the corresponding analysis of crystals of the rock salt structure and fluorite; general work conclusions are summarized.

\section{KEATING MODEL: POTENTIAL AND FORCE CONSTANTS}

Two types of interaction are considered between the crystal atoms (Fig. 1) within the Keating Model [1], as follow: two-particle defined by the bond stretching and three-particle due to bond-bending.

Please cite this article in press as: Gordienko A.B., Gordienko K.A., Kopytov A.V. Dynamics of crystal lattice with non-tetraedrical site in Keating Model. Science Evolution, 2016, vol. 1, no. 2, pp. 108-113. doi: 2500-1418-2016-1-2-108-113.

Copyright (C) 2016, KemSU. This is an open access article distributed under the terms of the Creative Commons Attribution 4.0 International License (http:// creativecommons.org/licenses/by/4.0/), allowing third parties to copy and redistribute the material in any medium or format and to remix, transform, and build upon the material for any purpose, even commercially, provided the original work is properly cited and states its license. This article is published with open access at http:/ science-evolution.ru/ 


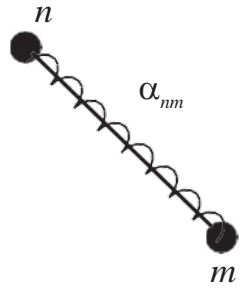

(a)

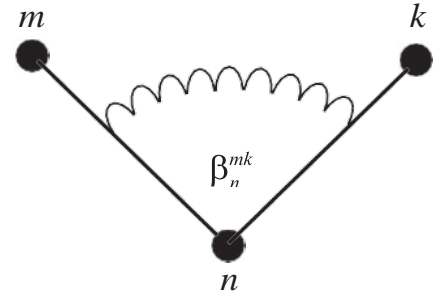

(b)
Fig. 1. Major interactions in the Keating Model.

Expression for potential energy of crystal using the activity label [6] is written as

$$
\begin{aligned}
U & =\frac{2}{A}{ }_{2} \sum_{n, m} \alpha_{n m}\left\{\mathbf{R}(n m) \mathbf{R}(n m)-\mathbf{R}^{0}(n m) \mathbf{R}^{0}(n m)\right\}^{2}+ \\
& +\frac{2}{A^{2}} \sum_{n, m, k>m} \beta_{n}^{m k}\left\{\mathbf{R}(n m) \mathbf{R}(n k)-\mathbf{R}^{0}(n m) \mathbf{R}^{0}(n k)\right\}^{2},
\end{aligned}
$$

where

$$
\begin{aligned}
\mathbf{R}(n m) & =\mathbf{R}(n)-\mathbf{R}(m), \\
\mathbf{R}^{0}(n m) & =\mathbf{R}^{0}(n)-\mathbf{R}^{0}(m) \\
\mathbf{u}(n) & =\mathbf{R}(n)-\mathbf{R}^{0}(n)
\end{aligned}
$$

and $\mathbf{R}^{0}(n), \mathbf{R}(n)$ - equilibrium and offset position of $n$ atom. $\alpha$ m and $\beta n$-parameters of two- and three-particle interactions that normally relate to the coefficient of rigidity, though the potential energy mode (1) does not allow the physical analogy in full; accordingly, $A$ - lattice parameter in case of cubic crystals or, for example, the average value of several crystals in case of other syngony. Summing as per $n$ is done for the whole crystal, $m$ and $k$ are limited within the model by first or second neighbors of the atom $n$. It should be noted that (1) is the initial work expression [1], that may be expanded including, by retention of the rotational invariance, the combined terms of sum that describe the stretch-stretch "interaction", as well as stretch-bends [22].

Computation of force constants, eg. [16], defined as derivatives

$$
\Phi \mu v(n m)=\left.\frac{\partial^{2} U}{\partial u_{\mu}(n) \partial u_{v}(m)}\right|_{\mathbf{R}=\mathbf{R}^{0}}, \mu, \nu=x, y, z
$$

requires consideration of "direct" and "indirect" bonds in the Keating Model, as per Fig. 2, 3 and results to the following expressions, accordingly

$$
\begin{aligned}
& \Phi_{\mu v}(n m)=\Phi_{\mu v}^{(\alpha)}(n m)+\Phi_{\mu v}^{(\beta)}(n m)= \\
& =-\frac{16}{A^{2}} \alpha_{n m} R_{\mu}^{0}(\mathrm{~nm}) R_{v}^{0}(\mathrm{~nm})- \\
& -\frac{4}{-} \sum_{n}^{m k}\left(R_{\mu}^{0}(n k) R_{v}^{0}(n k)+R_{\mu}^{0}(n m) R_{v}^{0}(n k)\right)- \\
& -\frac{4}{-} \sum \beta^{n k}\left(R^{0}(m k) R^{0}(m k)+R^{0}(m k) R^{0}(m n)\right) \\
& A^{2}{ }^{m}{ }^{m} \\
& \Phi \quad(m k)=\frac{4}{m^{m k}} R^{0}(n k) R^{0}(n m)
\end{aligned}
$$

As for heteropolar compounds, the set of force constants (6)-(7) should be expanded with regard to the long-range effect of the Coulomb interaction. In most cases, to solve this problem, including for this work, a point characteristic model is applied described in detail in [21].

\section{RESULTS AND DISCUSSION}

The software support of the lattice dynamics within the Keating Model is provided using the Python [23] software language, that is currently widely used in scientific and engineering estimations. VESTA [24] and
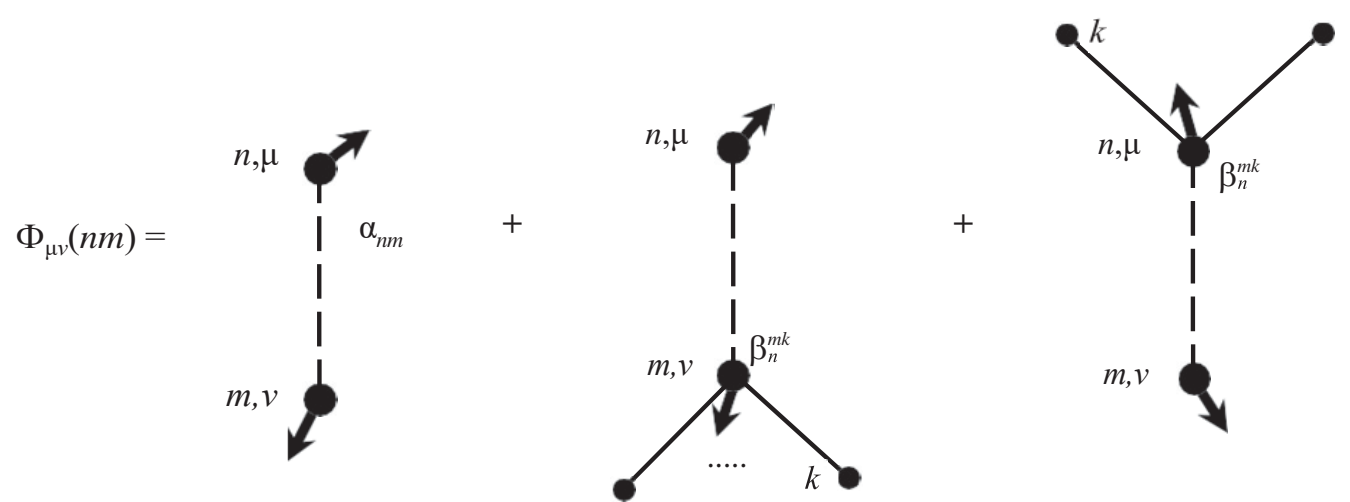

Fig. 2. Contributions to $\Phi_{\mu \nu}(\mathrm{nm})$ by atoms with the 'direct' bond.

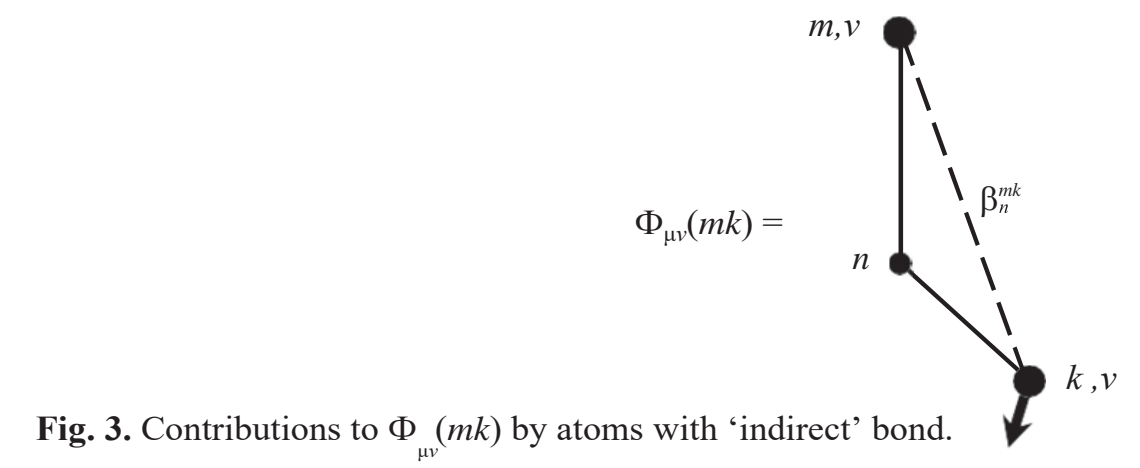


ESPlot [25] software programs are used for graphical display of crystal structures and phonon spectrum.

To check the consistency and accuracy of support, test estimations are performed of the lattice dynamics for the diamond $(\mathrm{C})$, and for the mono-layer superlattice (GaAs)1 (AlAs)1 with the growing axis (001). Parameters shown in works [1] and [9], accordingly, were used for calculations. Phonon spectrum is shown in Fig. 4, and specific frequency values are given in the Table 1. (Various units are here and elsewhere used for the convenient comparison of real calculation results versus estimations in other works or experimental data). As it is seen, in both cases the calculation results in the correct mode and sequence of vibrational edges and the frequency values satisfactory fit the results of other calculations and experimental data. Whereby, the reported differences are typical for the Keating Model and refer to the acoustic subspectrum, for which the frequency values, like in other analogous works, are increased versus the relevant experimental data.

Crystals with the structure of type cesium chloride $(\mathrm{CsCl}, \mathrm{CsBr})$ and the rock salt $(\mathrm{KCl}, \mathrm{KBr})$, that represent the wide class of alkali-halide crystals (AHC), appear to be the first convenient crystals to study the capacity to expand the scope of the Keating Model application. These compounds solidify to isometric systems with the face-centered and simple cubic lattice. Atoms are aligned in positions (000) and (a/2, $a / 2, a / 2)$, where $a$ - lattic constant, and have 8 and 6 nearest neighbors located in the cube corner and octahedron, Fig. 5. Parameters of short-range interactions $\left(\alpha=\alpha \mathrm{Me}-\mathrm{Hal}, \quad \beta=\beta \mathrm{Me}^{\mathrm{Hal}-\mathrm{Hal}}\right.$, $\beta_{2}=\beta \mathrm{H}^{\mathrm{Me}-\mathrm{Me}}$ ) and effective charges $(\mathrm{Z})$ are defined based on the consistency between the rated and experimental frequencies (or rated values by other authors) in the center point of the Brillouin zone (point G), and correct values LO-TO of breakage and are given in the Table 2.
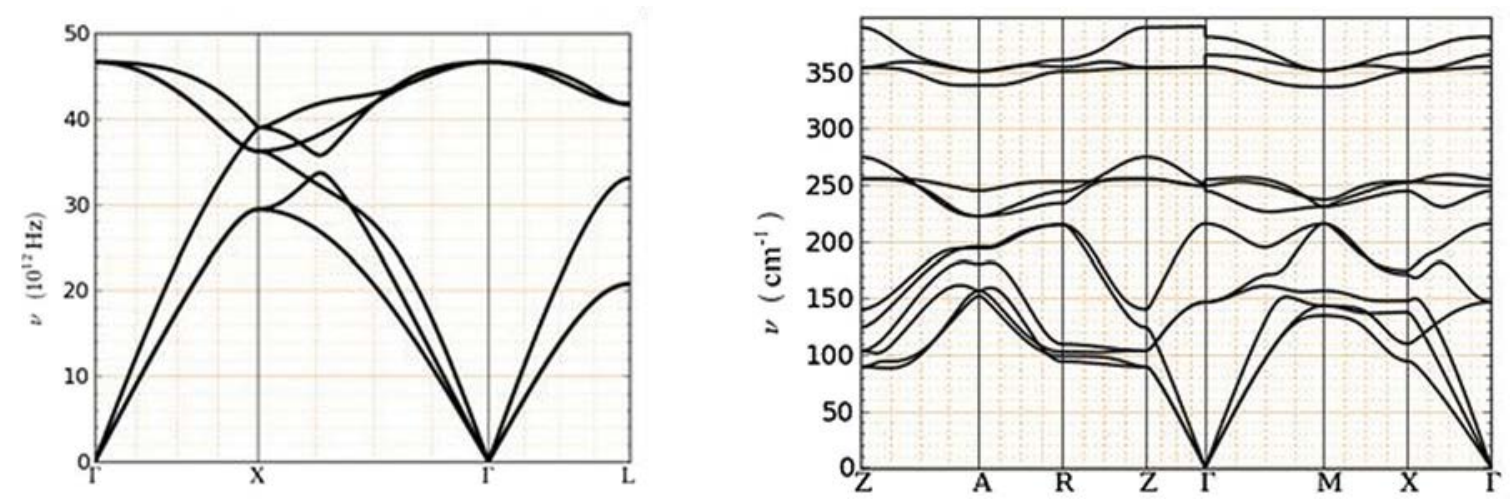

Fig. 4. Diamond phonon spectrum (C) (left) and the mono-layer supergrating (GaAs)1(AlAs)1 (right).

Table 1. Frequency of oscillation $\mathrm{C}$ and $(\mathrm{GaAs}) 1(\mathrm{AlAs}) 1$ in symmetric points of Brillouin zone

\begin{tabular}{|c|c|c|c|c|c|c|}
\hline \multicolumn{3}{|c|}{$\mathrm{C}$ (diamond) } & \multicolumn{4}{|c|}{$(\mathrm{GaAs}) 1(\mathrm{AlAs}) 1$} \\
\hline Symm. & $\begin{array}{l}\text { Real estimation } \\
\left(\mathrm{cm}^{-1}\right)\end{array}$ & $\begin{array}{l}{[26]} \\
\left(\mathrm{cm}^{-1}\right)\end{array}$ & Symm. & $\begin{array}{l}\text { Real estimation } \\
\left(\mathrm{cm}^{-1}\right)\end{array}$ & Estimation [9] & Experiment [9] \\
\hline$\Gamma$ & 1566 & 1555 & \multirow{3}{*}{$Г 5$} & $381 / 354$ & $379 / 352$ & $-/ 358$ \\
\hline$\Gamma$ & 705 & 870 & & $254 / 249$ & $254 / 248$ & $260 /-$ \\
\hline $\mathrm{L} 2$ & 1103 & 1477 & & $146 / 146$ & $146 / 146$ & - \\
\hline L3 & 1398 & 839 & \multirow{5}{*}{$\Gamma 3$} & $381 / 365$ & $386 / 360$ & $384 /-$ \\
\hline $\mathrm{L} 4$ & 1407 & 1197 & & $254 / 244$ & $252 / 246$ & $273 /-$ \\
\hline $\mathrm{X} 1$ & 997 & 979 & & 215 & 214 & 198 \\
\hline $\mathrm{X} 2$ & 1207 & 1212 & & & & \\
\hline X3 & 1313 & 1306 & & & & \\
\hline
\end{tabular}

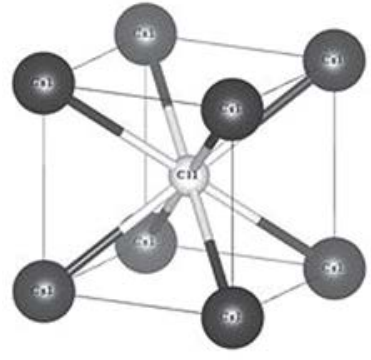

(a)

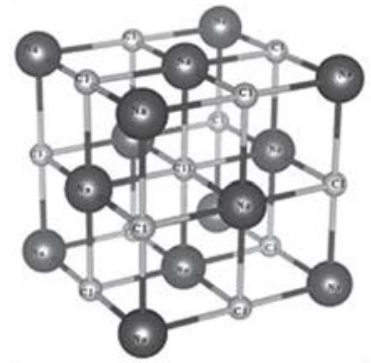

(b)
Fig. 5. Crystalline structure of $\mathrm{CsCl}(\mathrm{a})$ and и $\mathrm{Na} \mathrm{Cl}(\mathrm{b})$ type conjugation.
Table 2. Alkali-halide crystal structural and potential parameters

\begin{tabular}{|c|c|c|c|c|c|}
\hline Crystal & $\begin{array}{c}\text { Lattice } \\
\text { parameter } \\
(\AA)\end{array}$ & $\begin{array}{c}\alpha \\
(\mathrm{N} / \mathrm{m})\end{array}$ & $\begin{array}{c}\beta 1 \\
(\mathrm{~N} / \mathrm{m})\end{array}$ & $\begin{array}{c}\beta 2 \\
(\mathrm{~N} / \mathrm{m})\end{array}$ & $\begin{array}{c}\mathrm{Z} \\
(\mathrm{e})\end{array}$ \\
\hline $\mathrm{CsCl}$ & 4.088 & 0.93 & 0.05 & -0.10 & \pm 0.79 \\
\hline $\mathrm{CsBr}$ & 4.240 & 1.10 & 0.01 & -0.20 & \pm 0.86 \\
\hline $\mathrm{KCl}$ & 6.293 & 1.10 & 0.10 & 0.10 & \pm 0.69 \\
\hline $\mathrm{KBr}$ & 6.598 & 1.00 & -0.05 & -0.05 & \pm 0.71 \\
\hline
\end{tabular}


Phonon spectrum of crystals of the structure like $\mathrm{CsCl}$, calculated for several symmetric trends in the Brillouin zone is shown in Fig. 6. As it is seen, in general, the Keating Model offers satisfactory description of the frequency spectrum for a wide range of values in the wave vector. A distinctive feature is the perfect consistency in the frequency subspectrum of acoustic oscillation where the Keating Model normally predicts greater frequency values than observed. This can be explained, on the one hand, by the fact, that the model parameters in real estimations are defined by alignment of frequency as compared with the standard version, based on comparison of elastic constants, which does not guarantee the similar quality of frequency values. On the other hand, unlike diamond compounds, where the three-particle interaction parameters are positive, this case requires negative values either, which, as per calculations, are more preferential for tested structures.

The results for crystals of type $\mathrm{Na} \mathrm{Cl}$ are shown in the Fig. 7. Here, as for the $\mathrm{CsCl}$ type compounds, the Keating Model quite efficiently describes the vibrational spectrum, wherein the deviations against calculations, based on the BBFM method [20] containing seven parameters, are relatively small, when the general topology of phonon branches is fully reproduced. The value of $\beta$ parameter, as for crystals of type $\mathrm{CsCl}$, is also negative for $\mathrm{KBr}$, which can be taken systematic, given that similar parameters in calculations of works [10,16-20] for similar crystals are also negative in most cases.

The fluorite crystal ( $\mathrm{Ca} \mathrm{F}$ ) is challenging for purposes of this work, since its structure may be

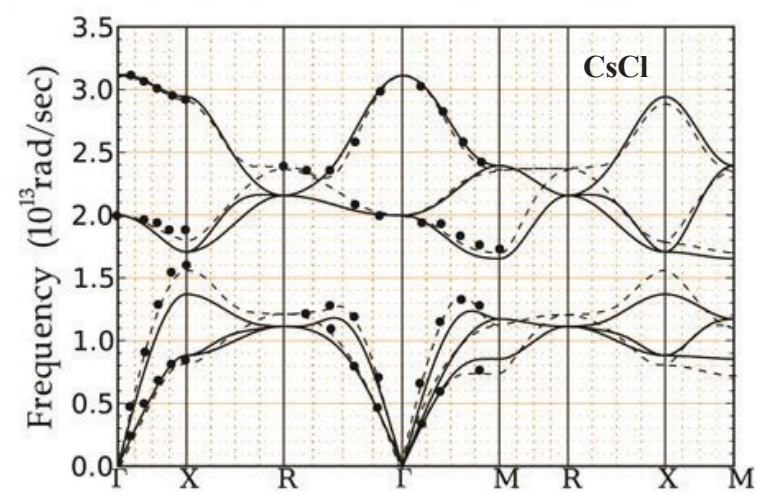

considered as the structure by the complexity degree in terms of compounds above. Fluorite solidifies in the cubic system with the face-centered lattice, and the lattice cell contains 3 atoms with coordinates $\mathrm{Ca}(0,0$, $0)$ and $\mathrm{F}( \pm a / 4, \pm a / 4, \pm a / 4)$, Fig. 8. The feature of this structure is the fluorine atom sub-system that forms the simple cubic lattice with the constant equal to $a / 2$. For the structure of $\mathrm{Ca} \mathrm{F} 2$, the nearest neighborhood contains the following: for atom $\mathrm{Ca}-8 \mathrm{~F}$ atoms in the cube corner, for $\mathrm{F}$ atom - $4 \mathrm{Ca}$ atoms (tetrahedron) and $6 \mathrm{~F}$ atoms (octahedron), which in view of symmetric interaction, results in six short-range parameters with values shown in the Table 3 with effective charges (in units of Table 2).

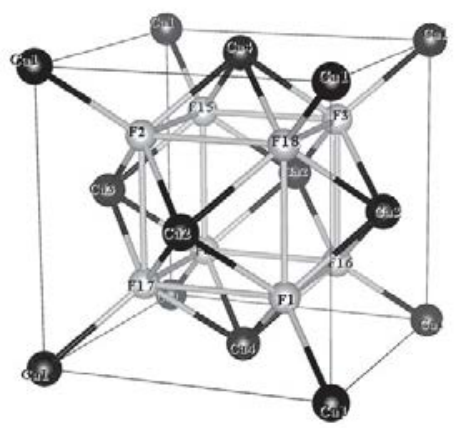

Fig. 8. Ca F2 crystalline structure.

Table 3. Short-range action parameters for $\mathrm{CaF} 2$

\begin{tabular}{|c|c|c|c|c|c|c|}
\hline$\alpha \mathrm{Ca}-\mathrm{F}$ & $\alpha \mathrm{F}-\mathrm{F}$ & $\beta \mathrm{CaFF}$ & $\beta \mathrm{FCaCa}$ & $\beta \mathrm{FFF}$ & $\beta \mathrm{FCaF}$ & $\mathrm{Z}$ \\
\hline 18.5 & 3.75 & -0.9 & 0.1 & 0.1 & -0.5 & \pm 1.5 \\
\hline
\end{tabular}

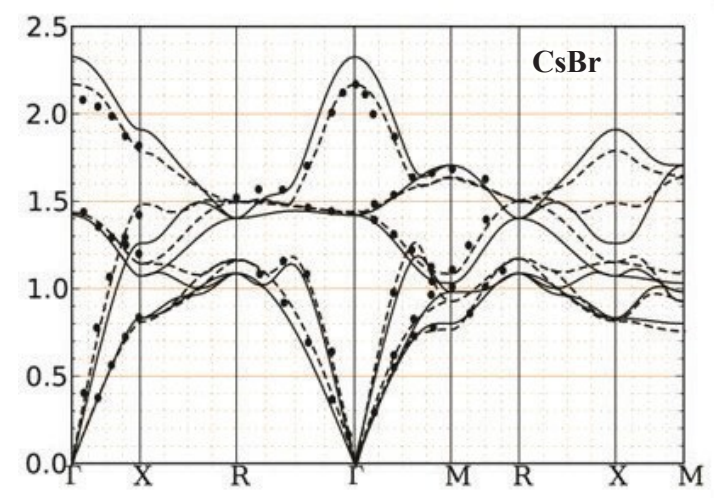

Fig. 6. $\mathrm{CsCl}$ and $\mathrm{CsBr}$ phonon spectrum: firm line - real estimation, dash-dot line - estimation and experiment [27].
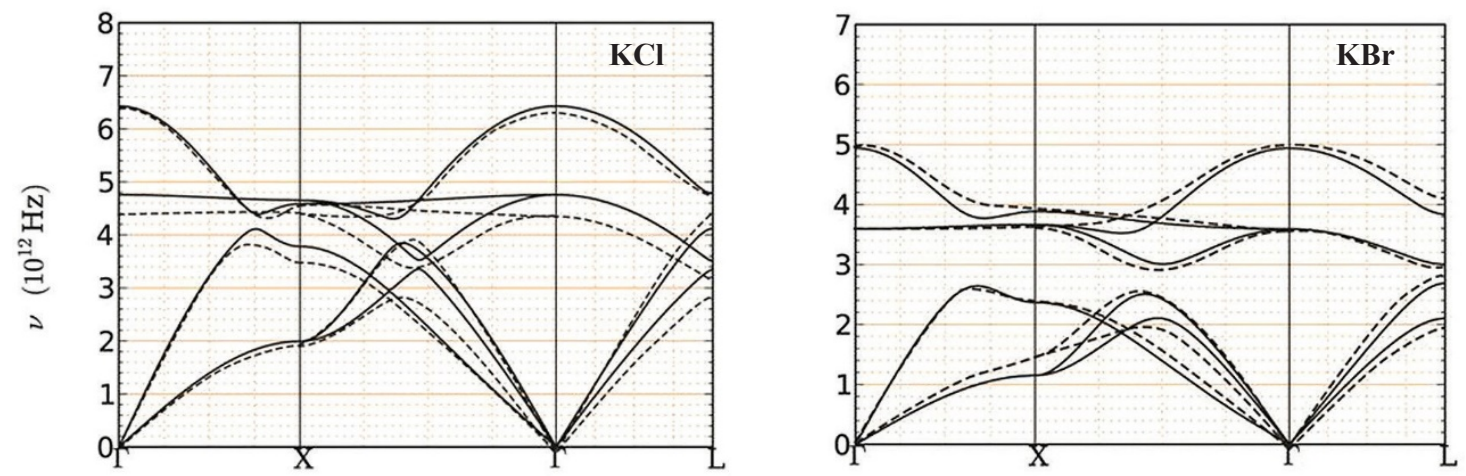

Fig. 7. $\mathrm{KCl}$ and $\mathrm{KBr}$ phonon spectrum: firm line - real estimation, dashed line -estimation in BBFM model [20]. 
Calculation results for $\mathrm{CaF} 2$ are shown in Fig. 9, and also given in Table 4. As it is seen, the Keating Model for the fluorite structure also results in the very good qualitative and quantitative description of the vibrational spectrum, being highly competitive with first-principles calculations.

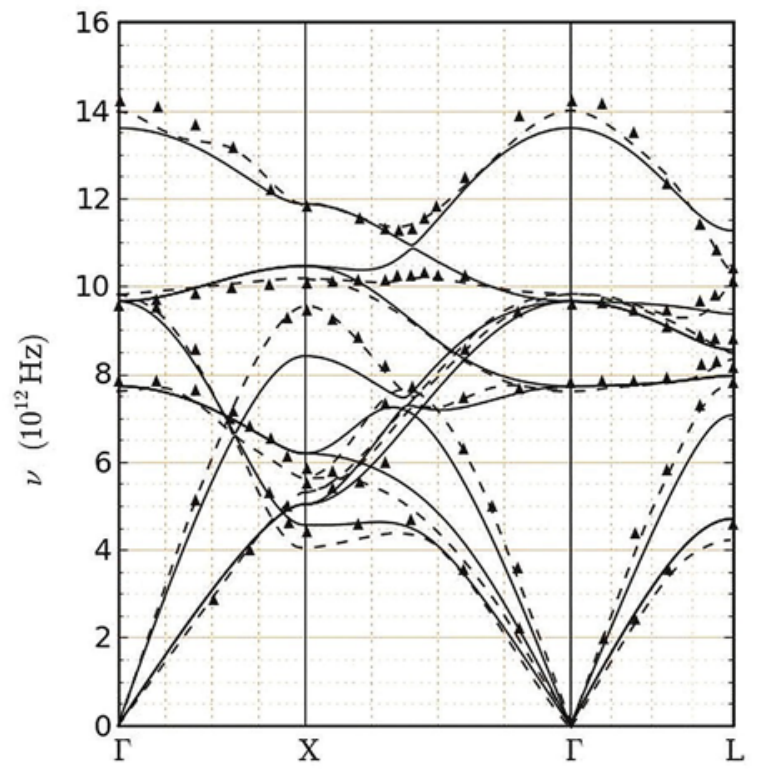

Fig. 9. Ca F2 phonon spectrum: lines - real estimation, dashed line - first-principles calculation [28], triangles - experiment [29].

Table 4. Comparison of rated and experimental freuency values of $\mathrm{CaF} 2$

\begin{tabular}{|l|c|c|c|c|}
\hline & $\begin{array}{c}\text { Real } \\
\text { estimation } \\
\left(\mathrm{cm}^{-1}\right)\end{array}$ & $\begin{array}{c}{[30]} \\
\left(\mathrm{cm}^{-1}\right)\end{array}$ & $\begin{array}{c}{[29]} \\
\left(\mathrm{cm}^{-1}\right)\end{array}$ & $\begin{array}{c}\text { Experiment } \\
{[31]} \\
\left(\mathrm{cm}^{-1}\right)\end{array}$ \\
\hline LO & 453.55 & 453.82 & 466 & 463 \\
\hline Raman & 321.90 & 309.56 & 327 & 322 \\
\hline TO & 257.46 & 225.96 & 253 & 257 \\
\hline
\end{tabular}

The most notable differences of the spectrum obtained in these calculations from first-principles calculations and experimental data are reported for acoustic branches at the $\mathrm{X}$ point, for which the Keating
Model leads to somewhat understated frequency values on the X-F line, where the avoided crossing of highfrequency mode is seen, as well as at L point, where, on the contrary, the frequency of oscillation breakup is somewhat increased versus the results in [28, 29]. It is seen in data in the Table 3 that for most intense three-particle interactions in $\mathrm{CaF} 2$, that refer to atomic chains of type F-Ca-F and Ca-F-F, the parameter values are also negative, and this again proves the feature of the Keating Model stated above to apply to compounds with the structure, atomic site and, respectively, the geometric bond configuration differ from "standard" values for this method.

It should be noted that the use of negative values in the Keating Model for short-range behavior consistent with the bond bending, in view of its initial statement [1], may seem, at the first glance, unreasonable, since this paper provide arguments in favor of their positivity. At the same time, negative values occur even in calculations for the diamond-like systems, such as [22], where they are defined based on the comparison with the spectrum of frequencies, and as such, the parameter $\beta$ may be taken as the value within the meaning of "effective" and implicitly including additional interactions as follow: as shown in $[32,33]$, the accuracy enhancement in the Keating Model requires consideration of, at least, 4 particles ( 4 bonds and 2 bond angles).

\section{CONCLUSION}

The calculation results of the lattice dynamics in this paper show that the Keating Model in its initial statement may be efficiently applied to compounds with the atomic site that differs from that of tetrahedral and may, inter alia, include multiple types for a single crystal. The property set specified by the structure and symmetry of crystals of the tested type is sufficient for qualitative and quantitative description of vibrational spectrum, despite the complexity of the geometric bond structure between atoms. This suggests that the Keating Model may be applicable for crystal compounds which are more complicated in terms of their structure.

The work is supported by the state assignment 3.235.2014K.

\section{REFERENCES}

1. Keating P.N. Effect of Invariance Requirements on the Elastic Strain Energy of Crystals with Application to the Diamond Structure. Physical Review, 1966, vol. 145, no. 3, pp. 637-645, doi: 10.1103/PhysRev.145.637.

2. Martin R.M. Elastic Properties of ZnS Structure Semiconductors. Physical Review, 1970, vol. 1, no. 10, pp. 4005-4011, doi: 10.1103/ PhysRevB.1.4005.

3. Bashenov V.K., Marvakov D.I., Petukhov A.G. Lattice Dynamics of Diamon d-Type Crystals from Keatong's Valence-Force Field. Physica Status Solidi (b), 1978, vol. 88, no. 2, pp. K161-K164. doi: 10.1002/ pssb.2220880265.

4. Betini M. Zone-Centered Phonons in Ternary Compounds of Chalcopyrite Structure. Physica Status Solidi (b), 1975, vol. 69, no. 1, pp. 201-212. doi: 10.1002/pssb.2220690123.

5. Koschel W.H., Betini M. Zone-Centered Phonons in $\mathrm{A}^{\mathrm{I}} \mathrm{B}^{\mathrm{III}} \mathrm{S} 2$ Chalcopyrites. Physica Status Solidi (b), 1975, vol. 72 , no. 2, pp. 729-737. doi: 10.1002/pssb.2220720233.

6. Skachkov S.I. and Tyuterev V.G. Vnutrennie smeshchenija ionov v kristallakh s reshetkoy khal'kopirita v usloviyakh odnorodnoy deformatsii [Internal ionic displacement in crystals with chalcopyrity lattice during homogenous deformation]. Fizika [Physics], 1981, no. 5, pp. 72-77.

7. Poplavnoi A.S., Tjuterev V.G. Lattice Dynamics of AIIBIVCV2 and AIBIIICVI2 Semiconductors with Chalcopyrity Lattice in a Rigid-Ion Model. Journal de Physique Colloques, 1975, vol. 36, pp. 169-170. doi: 10.1051/ jphyscol:1975331.

8. Tyuterev V.G., Skachkov S.I. Lattice Dynamics, Thermodynamics and Elastic Properties of Cd GeAs2, Nuovo Cimento, 1992, vol. 14, no. 11, pp. 1097-1103. doi: 10.1007/BF02456762. 
9. Tyuterev V.G. Reshetochnaya dinamika monosloynoy sverkhreshetki (GaAs)1 (AlAs)1 (001) [Lattice dynamics of monolayer superlattice (GaAs) 1 (AlAs) 1 (001). Bulletin of HEI]. Fizika [Physics], 1989, no. 11. 127 p.

10. Narayana Murty J.V.S.S., Ramji Rao R., Lattice Dynamics of ZrC Using Keating's Approach. Physica Status Solidi (b), 1981, vol. 104, no. 2, pp. 691-696. doi: 10.1002/pssb.2221040236.

11. Davydov S.Yu. Vliyanie netsentral'nykh sil na temperaturnuyu zavisimost' uprugikh postoyannykh kristallov s reshetkoy $\mathrm{Na} \mathrm{Cl}$. [Impact of non-central forces on the temperature dependence of elastic constant crystals with $\mathrm{Na} \mathrm{Cl} \mathrm{lattice].} \mathrm{Fizika}$ tverdogo tela [Solid state science], 1973, vol. 15, no. 11, pp. 3458-3460.

12. Davydov S.Yu., Nikanorov S.P. Uprugie svoistva kristallov ANB8-N i ionnost' [Ealstic properties of crystalls A NB8-N and electrovalence]. Fizika tverdogo tela [Solid state science], 1974, vol. 16, no. 1, pp. 210-213.

13. Grabov V.M., Davydov S.Yu., Mironov Yu.P., Juigo A.M. Uprugie svoystva i sily svyazi v polumetallakh V gruppy i ikh splavakh [Elastic properties and bond strength in $\mathrm{V}$ group semimetals and alloys]. Fizika tverdogo tela [Solid state science], 1985, vol. 27, no. 7, pp. 2017-2024.

14. Davydov S.Yu. Uprugie svoystva grafena: model Kitinga. [Graphene elastic properties: Keating Model]. Fizika tverdogo tela, [Solid state science], 2010, vol. 52, no. 4, pp. 756-758.

15. Davydov S.Yu. Uprugie moduli tret'ego poryadka odnoslozhnogo grafena. [Elastic modules of mono-layer graphene of third order]. Fizika tverdogo tela [Solid state science], 2011, vol. 53, no. 3, pp. 617-619.

16. Kushwaha M.S. Lattice Dynamics of Sodium and Rubidium Halides. Nuovo Cimento, 1980, vol. 60, no. 2, pp. $201-214$. doi: 10.1007/BF02728228.

17. Kushwaha M.S. Normal Modes of Vibrations in Transition Metal Oxides. Physica B+C, 1982, vol. 112B, pp. 232-236. doi: 10.1016/0378-4363(82)90023-7.

18. Kushwaha M.S. Bond-bending Forces in the Crystal Dynamics of Cs-halides, Physica B+C, 1984, vol. 123B, pp. 300-312. doi: 10.1016/0378-4363(84)90106-2.

19. Kushwaha M.S. Lattice Dynamics of Alkaline-Earth Oxides. Journal of Chemical Physics, 1982, vol. 7, no. 11, pp. 5693-5698. doi: 10.1063/1.443776.

20. Kushwaha M.S. Lattice Dynamics of Potassium Halides ( $\mathrm{KCl}, \mathrm{KBr}$ and $\mathrm{KI})$. Journal of the Physical Society of Japan, 1980, vol. 48, no. 2, pp. 377-383. doi: 10.1143/JPSJ.48.377.

21. Born M., Kun Kh. Dinamicheskaya teoriya kristallicheskikh reshetok [Dynamics theory of crystal lattice]. Moscow: Publ. Inostrannaya literatura, 1958. $488 \mathrm{p}$.

22. Fu H, Ozoliņš V., Zunger A. Phonons in GaP Quantum Dots. Physical Review, 1999, vol. 59, no. 4, pp. $2881-2887$. doi: 10.1103/PhysRevB.59.2881.

23. Prokhorenok N.A. Python 3 and PyQt. Software program elaboration. St. Petersburg: BHV-Peterburg, 2013.704 p.

24. Momma K., Izumi F. VESTA 3 for three-dimensional visualization of crystal, volumetric and morphology data. Journal of Applied Crystallography, 2011, vol. 44, pp. 1271-1276. doi: 10.1107/S002889811038970.

25. Gordienko A.B. State registration certificate for software program. Patent RF, no. 2016617462, 2016.

26. Kane E.O. Phonon spectra of diamond and zinc-blende semiconductors. Physical Review B, 1985. vol. 131, no. 12, pp. 7865-7876. doi: 10.1103/PhysRevB.31.7865.

27. Agrawal B.S. The Lattice Dynamics of $\mathrm{CsCl}, \mathrm{CsBr}$, and CsI. Solid State Communications, 1974. vol. 14. pp. $239-244$. doi: 10.1016/0038-1098(74)90843-6.

28. Wang Y., Zhang L. A., Shang S., Liu Z.-K., Chen, L.-Q. Accurate calculations of phonon dispersion in $\mathrm{CaF}_{2}$ and $\mathrm{Ce} \mathrm{O}_{2}$. Physical Review B, 2013, vol. 88, no. 2, pp. 024304(1-5). doi: 10.1103/PhysRevB.88.024304.

29. Schmalzl K., Strauch D., Schober H. Lattice-Dynamical and Ground-State Properties of Ca F2 Studied by Inelastic Neutron Scattering and Density-Functional Methods. Physical Review B, 2003, vol. 68, no. 14, pp. 144301 (1-12). doi: 10.1103/PhysRevB.68.144301.

30. Himadri R. Somi, Sajeev K. Gupta, Mina Talati, Prafulla K. Jha. Ground state and lattice dynamic study of ionic conductors $\mathrm{CaF}_{2}, \mathrm{SrF}_{2}$ and $\mathrm{BaF}_{2}$ using density functional theory. Journal of Physics and Chemistry of Solids, 2011, no. 72, pp. 934-939. doi: 10.1016/j.jpcs.2011.04.018.

31. Kaiser W., Spitzer W.G., Kaiser R.H., Howarth L.E Infrared Properties of $\mathrm{CaF}_{2}, \mathrm{SrF}_{2}$ and BaF2. Physical. Review B, 1962, vol. 127, no. 6, pp. 1950-1954. doi: 10.1103/PhysRevB.127.1950.

32. Abhijet P., Luiser M. and Klimeck G. Modified Valence Force Field Approach for Phonon Dispersion: from Zinc-blende Bulk to Nanowires. Journal of Computational Electronics, 2010, vol. 9, pp. 160-172. doi: 10.1007/s10825-010-0332-9.

33. Steiger S., Salmani-Jelodar M., Areshkin D., Paul A., Kubis T., Povolotskyi M., Park H-H, and Klimeck G. Enhanced Valence Force Field Model for the Lattice Properties of Gallium Arsenide. Physical Review, 2011, vol. 84, pp. 155204(1-11). doi: 10.1103/ PhysRevB.84.155204.

\section{Aleksey B. Gordienko}

Dr.Sci.(Phys.-Math.), Professor, Professorship of Theoretical Physics, Basic Science Institute, Kemerovo State University, Kemerovo, Russian Federation

\section{Kirill A. Gordienko}

Master's student, Basic Science Institute, Kemerovo State University, Kemerovo, Russian Federation

\section{Anatoliy V. Kopytov}

Cand.Sci.(Phys.-Math.), Assistant Professor at the Professorship of Theoretical Physics, Basic Science Institute, Kemerovo State University, Kemerovo, Russian Federation 